\title{
Rendimento industrial de filetagem da tilápia tailandesa (Oreochromis spp.)
}

[Industrial filefish processing yield of Thailand tilapia (Oreochromis spp.)]

\author{
L.M.S. Pinheiro ${ }^{1}$, R.T. Martins ${ }^{2}$, L.A.S. Pinheiro ${ }^{1}$, L.E.L. Pinheiro ${ }^{1}$ \\ ${ }^{1}$ TECNOGEN - Consultoria e Projetos Inovadores \\ Rua Artur Itabirano, 65 \\ 31275-020 - Belo Horizonte, MG \\ ${ }^{2}$ Escola de Veterinária - UFMG - Belo Horizonte, MG
}

\begin{abstract}
RESUMO
Avaliaram-se o rendimento de filetagem e os valores percentuais das partes de tilápia tailandesa (Oreochromis spp.), no âmbito de uma empresa em Minas Gerais, durante o período de janeiro a novembro de 2004. Foram processadas 4260 tilápias (2560 quilos), registrando-se os pesos totais dos peixes e de suas partes principais, o desempenho da mão-de-obra e o tempo gasto no processo. Os peixes foram distribuidos em três classes de peso $(300$ a $600 \mathrm{~g}$; 601 a $800 \mathrm{~g}$ e 801 a $1000 \mathrm{~g}$ ) O rendimento médio de filetagem foi de $31,0 \%$, variando de $28,9 \%$ a $33,6 \%$, complementado por $36,0 \%$ de cabeça e vísceras, $8,0 \%$ de pele, $22,0 \%$ de resíduo ósseo e 3,0\% de restos de toilet. Não houve diferença no rendimento de filetagem $(\mathrm{P}>0,05)$, entre as três classes de pesos. Verificaram-se que as variações dos percentuais e o desempenho dos operários têm impacto na competitividade da empresa.
\end{abstract}

Palavras-chave: tilápia, rendimento de filetagem, produção industrial

\begin{abstract}
This experiment was carried out in order to evaluate some technical aspects of the industrial processing of tilapias (Oreochromis spp.), with emphasis on the filefishing profitability in an industry, located in Minas Gerais state, Brazil. During a period between January and November, 2004, 4260 fishes, totalling $2560 \mathrm{~kg}$, with individual weights ranging from 300 to $1000 \mathrm{~g}$ (mean individual weight of $600 \mathrm{~g}$ ) were processed. Data collected comprehended total body weight, and parts weight, such as: head and viscera, filefish, skin, carcass residue and "toilet" residue, aiming to correlating the per cent value of each part, also considering: fish size method of cutting and processing time. The net filefish per cent was 31.0\%, ranging between $28.9 \%$ to $33.6 \%$, complemented by: head-viscera $36.0 \%$; skin $8.0 \%$; carcass residue $22.0 \%$ and toilet $3.0 \%$. No statistical differences in net filefish gains in three different classes of sizes of fishes (300-600g; 601-800g and 801-100g) (P>0.05) were detected. In addition, the variation of net yield, as well as labor efficiency, had a particular impact in the company competitvity.
\end{abstract}

Keywords: tilápia, Oreochromis spp., filefish processing, fish industry

\section{INTRODUÇÃO}

A piscicultura é reconhecida como uma importante atividade agroindustrial, capaz de gerar grande retorno financeiro para os produtores e para as indústrias processadoras de peixes, numa visão sistêmica de cadeias produtivas. Entre as diversas espécies cultivadas, destacam-se as tilápias (Oreochromis spp.), originárias da África, da Jordânia e de Israel, tendo sido introduzidas no Brasil na década de setenta. Entre as espécies cultivadas para fins

Recebido em 19 de janeiro de 2005

Aceito em 31 de outubro de 2005

E-mail: luizmarcelovet@hotmail.com 
industriais, destacam-se a tilápia do Nilo (Oreochromis niloticus), a tilápia vermelha (híbrido formado por até quatro espécies diferentes) e a chitralada ou tailandesa, que é uma variedade melhorada da tilápia do Nilo. A tilápia tailandesa constitui numa linhagem que passou por intensa seleção iniciada ao final dos anos 60 , quando houve a introdução de linhagem pura de tilápia do Nilo na Tailândia. Como resultado dessa seleção, a qualidade da tilápia tailandesa superou a qualidade da tilápia do Nilo.

A produção mundial de tilápias tem crescido acentuadamente e, atualmente, é uma das espécies mais indicadas para o cultivo intensivo, devido às suas qualidades para a produção industrial e à excelente textura de carne (Clement e Lovell, 1994). No Brasil, nos últimos anos, vários empreendimentos de porte foram ou estão sendo implantados, estabelecendo-se consistentes bases tecnológicas de cultivo e de processamento de tilápias, destacando-se o cultivo da tilápia tailandesa.

O rendimento do filé é o item de maior valor econômico, o qual varia de acordo com o domínio tecnológico das empresas processadoras. Na literatura foram encontrados dados de rendimentos de filé de tilápia do Nilo, variando de $25,4 \%$ até valores próximos a $42,0 \%$, em função do peso corporal, métodos de filetagem, comparação da forma de decaptação, remoção da pele e nadadeiras (Clement e Lovell, 1994; Macedo-Viegas et al., 1997; Souza e Macedo-Viegas, 2001; Souza et al., 1999, 2002). Ribeiro e Miranda (1997) classificaram a tilápia entre os peixes cultivados de menor rendimento de filé quando comparada ao catfish e ao surubim. Clement (1992) citou um rendimento de filé da ordem de 33,0\%; posteriormente, Clement e Lovell (1994) observaram que o rendimento não ultrapassava $25,4 \%$.

No Brasil, Souza et al. (1997a,b) relataram rendimento de filé em função do tamanho dos peixes e observaram melhor rendimento $(37,3 \%)$ para a classe de 250 a $300 \mathrm{~g}$. Em outro estudo, foram obtidos rendimentos de $36,7 \%$ e $32,9 \%$, de acordo com a faixa de peso estipulada e as variações nos métodos de filetagem utilizados (Sousa et al., 1997a). Pádua et al. (1998) observaram rendimento de filetagem em torno de $30 \%$, quando utilizaram peixes com média de peso final de $300 \mathrm{~g}$.
Souza (2003) realizou um experimento com cem tilápias do Nilo (O. niloticus), com peso variando entre 500 e $800 \mathrm{~g}$. Os peixes foram divididos em três classes de acordo com os pesos, 1(500 a $600 \mathrm{~g}), 2(601$ a $700 \mathrm{~g})$ e 3(701 a $800 \mathrm{~g}$ ), sendo a filetagem feita por apenas uma pessoa, que observou rendimentos de filetagem de $38,5 \%$, $40,2 \%$ e $40,4 \%$ para as classes 1,2 e 3 , respectivamente, valores superiores aos relatados por Souza et al. (1997a,b) e Pádua et al. (1998).

Os objetivos deste trabalho foram avaliar numa empresa, situada em Minas Gerais, com Inspeção Federal, o rendimento de filetagem industrial e sua relação com o peso ao abate; a razão ideal entre tempo de processamento e rendimento de filetagem; a relação entre rendimento de amostragem e rendimento industrial.

\section{MATERIAL E MÉTODOS}

Utilizaram-se 4260 tilápias tailandesas, com peso variando de 300 a $1000 \mathrm{~g}$, sendo a média de $600 \mathrm{~g}$. Não foi possível padronizar o sexo, mesmo considerando que cerca de $95 \%$ são machos devido à reversão sexual, cujo processo não pôde ser descrito por motivos de segurança empresarial. Todos os peixes foram alimentados com rações comerciais peletizadas, próprias para recria e engorda.

Todo o fluxo descrito, em seguida, faz parte do conjunto de normas técnicas implantado na empresa, tais como: boas práticas de fabricação (Brasil, 1997) e análise de perigos e pontos críticos de controle - APPCC (Brasil, 1998). A caracterização dos procedimentos utilizados neste experimento considerou os principais itens do conjunto dessas normas técnicas.

Os peixes passaram por um período de 48 horas sem alimentação, no rio, dentro do próprio tanque-rede, etapa de depuração. Em seguida, foram despescados, seguindo-se o abate por meio de choque térmico, em monoblocos com gelo de água potável clorada (5ppm de cloro), na proporção de duas partes de gelo para uma de peixe. Em seguida, os monoblocos com os peixes foram transportados em caminhão frigorífico, percorrendo a distância de aproximadamente $20 \mathrm{~km}$ até a indústria. 
$\mathrm{Na}$ indústria, os peixes foram separados do gelo, inspecionados e classificados. As pesagens foram feitas em balança digital, de precisão de $0,2 \mathrm{~kg}$, seguindo-se as lavagens, realizadas com água clorada (5ppm), sob pressão, no interior de cilindro próprio, feito de aço inoxidável, previamente higienizado, de acordo com as normas HST (higiênico sanitário tecnológicas). Esse processo é contínuo, conduzindo os peixes automaticamente e sem manuseio, até o óculo de entrada do setor de filetagem.

O setor de filetagem era composto de uma mesa retangular, de aço inoxidável com uma calha coletora central e uma torneira em cada lado para cada um dos seis operadores que ela comportava. A equipe de processadores era composta por 12 pessoas, treinadas e paramentadas com equipamentos de proteção individual. Em cada um dos lados, o primeiro operador descabeçava e eviscerava, o segundo e o terceiro retiravam os filés do esqueleto, o quarto retirava a pele dos filés, enquanto o quinto e o sexto realizavam a limpeza final ou toilet. Os restos de toilet eram destinados à graxaria, sendo posteriormente, enviados ao aterro sanitário.

$\mathrm{Na}$ filetagem, empregou-se a seguinte técnica: o descabeçamento era realizado com um corte no sentido dorso-ventral, o mais rente possível do opérculo, o que requer manter as tilápias em decúbito ventral, em seguida fazia-se a evisceração, por meio de facas apropriadas. Os filés eram retirados do esqueleto, no sentido crânio-caudal e dorso-ventral, sendo um lado de cada vez. A pele era removida no sentido caudocranial, com a ajuda de um garfo próprio, seguindo-se a realização de toilet nos filés, para a retirada dos restos de pele e os espinhos presentes na parte cranial destes. Após toilet, os filés eram pesados em balança digital, com precisão de $2 \mathrm{~g}$. Os dados referentes ao dia, à hora, à duração do processo, ao peso total processado e ao peso obtido de filés eram lançados em planilhas de Excel.

Após processamento, os filés eram embalados a granel e comercializados como filés frescos; ou congelados. Os filés congelados eram imersos em gelo fundente $0^{\circ} \mathrm{C}$ (glazing) para evitar o escurecimento da carne em conseqüência da queima pela baixa temperatura de congelamento $\left(-20^{\circ} \mathrm{C}\right)$. Após o glazing, os filés eram embalados em pacotes de aproximadamente $500 \mathrm{~g}$ para comercialização na forma congelada.

Em três dias alternados, foram feitas pesagens dos peixes inteiros e, isoladamente, das cabeças e vísceras, dos resíduos ósseos, das peles e dos filés, o que permitiu obter o percentual de cada parte pesada. Os dados obtidos nesses dias constituíram o grupo de rendimento amostral que, posteriormente, foi comparado com o grupo de rendimento industrial, trabalhados em cinco dias alternados, ao longo do período experimental, com intuito de avaliar a mão-deobra, em rendimento de filetagem e tempo de processamento.

Foram realizadas 13 coletas de dados diárias distintas, em nove dias, no período de janeiro a novembro de 2004, incluindo o experimento amostral de rendimento de filetagem individual de peixes divididos em três classes de peso. Nesse último experimento, foram processados 10 peixes em cada classe (1-300 a 600g, 2-601 a $800 \mathrm{~g}$ e $3-801$ a $1000 \mathrm{~g}$ ), totalizando 30 peixes.

Os dados foram relacionados com o peso de abate e com o rendimento industrial comparado ao amostral. Todo o conjunto de variáveis, incluindo as médias $\mathrm{e}$ as porcentagens, foi analisado utilizando-se delineamento inteiramente casualizado, testando dois tratamentos (rendimento amostral $\times$ rendimento industrial), com diferentes números de repetições (cinco e 10, respectivamente). As médias de rendimento de filetagem (\%) e de tempo de processamento $(\mathrm{g} / \mathrm{min})$ foram comparadas pelo teste $\mathrm{t}$ de Student (Sampaio 2002).

Realizou-se, também, análise descritiva dos aspectos econômicos, considerando a razão tempo $\times$ rendimento dos filés obtidos.

\section{RESULTADOS E DISCUSSÃO}

A Tab. 1 mostra o volume processado em cada dia, cujo total acumulado, durante o período do experimento, foi de $2560 \mathrm{~kg}$ de peixe. 
Pinheiro et al.,

Tabela 1. Rendimento de filetagem de tilápia, por dia de processamento, no ano de 2004

\begin{tabular}{ccccccc}
\hline Dia/mês & Cabeça e vísceras & Filé & Pele & Resíduo & Toilet & Total \\
\hline \multicolumn{7}{c}{} \\
\hline $21 / 01$ & 33,2 & 28,2 & 7,7 & 20,8 & 3,3 & 93,2 \\
$22 / 01$ & 15,2 & 11,9 & 3,2 & 9,0 & 1,6 & 41,0 \\
$3 / 02$ & - & 82,3 & - & - & - & 275,2 \\
$19 / 02$ & - & 7,9 & - & - & - & 25,2 \\
$3 / 03$ & - & 85,4 & - & - & - & 274,4 \\
$31 / 03$ & 10,4 & 9,6 & 1,9 & 5,9 & 0,7 & 28,6 \\
$29 / 04$ & - & 201,0 & - & - & - & 696,0 \\
$28 / 05$ & - & 358,0 & - & - & - & 1126,4 \\
\hline Total & 58,8 & 784,3 & 12,8 & 35,7 & 5,6 & 2560,0 \\
\hline$\%$ & 36,0 & 31,0 & 8,0 & 22,0 & 3,0 & $100,0 \%$ \\
\hline
\end{tabular}

As porcentagens de cabeça e vísceras, de pele, de resíduo ósseo e de toilet foram calculadas utilizando-se o total em quilogramas, dos dias em que foram pesadas essas partes $(93,2 ; 41,0$ e $28,6 \mathrm{~kg}$ ), ou seja, $162,8 \mathrm{~kg}$. A porcentagem de filé foi calculada relacionando o valor total obtido $(784,3 \mathrm{~kg})$, com o peso total de peixes $(2560 \mathrm{~kg})$, o que resultou no valor médio de $31,0 \%$ de rendimento de filetagem. Ressalta-se que apenas em três dias, nos quais o volume trabalhado era reduzido, foi possível proceder à pesagem de todas as partes dos peixes, não interferindo, assim, no processamento industrial. Nota-se, que todas as partes dos peixes $(100 \%)$ foram recuperadas (Tab. 1).

O valor médio de rendimento de filetagem $(31,0 \%)$ observado situa-se na média esperada, entre $27,0 \%$ e $36,0 \%$, segundo Souza et al. (1997a, b) e Pádua et al. (1998). Salienta-se que, na maioria dos casos, os dados provêm de avaliações em pequena escala, o que não ocorreu neste experimento, pois foram analisados 4260 peixes, ou seja, $2560 \mathrm{~kg}$. Esse rendimento pode refletir o ainda incompleto domínio de tecnologias de processamento pela empresa, o que é agravado por problemas operacionais diversos, entre os quais se encontram os recursos humanos em formação. Não foi possível avaliar os métodos de filetagem industrial em outras empresas, pois, devido a razões comerciais, não há descrições disponíveis.

Neste trabalho, a empresa considerou o experimento, como uma avaliação de seu domínio tecnológico. Segundo a literatura consultada, este estudo é um dos poucos realizados dentro de um frigorífico, portanto, o valor obtido de $31,0 \%$ pode ser considerado bem próximo ao real aproveitamento industrial de tilápias, no processo de filetagem.

Os resultados de rendimento de filetagem, por dia de processamento, variaram de $28,9 \%$ a $33,6 \%$, sendo que a média foi de $31,0 \%$ ao longo do período de acompanhamento (janeiro a maio de 2004). As planilhas de check-list de análise de perigos e pontos críticos de controle (Brasil, 1998), implantadas no frigorífico, foram observadas durante esse período, o que permitiu verificar a não ocorrência de alguma alteração que influenciasse no experimento.

São muitos os fatores que condicionam o rendimento de filetagem, devendo ser incluídos entre esses o grau de mecanização, o método de filetagem (ordem de retirada da pele e filé, remoção ou não da cabeça e nadadeiras para filetar, tipo de corte realizado na decapitação) e a destreza do filetador (Souza et al., 1999; Souza, 2001; Souza et al., 2002).

Sob o ponto de vista econômico, as tilápias são consideradas, quando comparadas com outros peixes cultivados, como sendo as de menor rendimento de filetagem (Clement, 1992; Clement e Lovell, 1994; Ribeiro e Miranda, 1997; Pádua et al. 1998). Entretanto, segundo esses autores, as melhorias em rendimento podem ser conquistadas com tecnologias (método de filetagem, pesos dos peixes) e com um melhor condicionamento dos recursos humanos. Apesar do rendimento de filetagem em parte inferior àquele obtido com outros peixes, as tilápias, atualmente, são consideradas como as mais indicadas para o cultivo intensivo, tanto pela textura da carne, quanto pelas suas outras qualidades em produção (Clement e Lovell 1994). 
Nos dias em que as pesagens contemplaram apenas os peixes inteiros, os filés obtidos constituíram o rendimento industrial, tendo sido gastos 15 horas e 43 minutos para processar $2397,2 \mathrm{~kg}$ de peixe inteiro, ou seja, $2,073 \mathrm{~kg} / \mathrm{min}$. Os dias de pesagem dos peixes inteiros e suas partes constituíram o rendimento amostral. Verificou-se que em três horas e 42 minutos foram filetados $162,8 \mathrm{~kg}$ de peixe inteiro, o que representou $0,854 \mathrm{~kg} / \mathrm{min}$, sendo essa diferença significativa $(\mathrm{P}<0,05)$. Ressalta-se que as pesagens de cabeça e vísceras, pele, carcaça e restos de toilet não influenciaram no tempo de processamento, pois foram feitas por outros funcionários.

$\mathrm{O}$ rendimento de filetagem industrial e o amostral, 31,2\% e 30,4\%, respectivamente, não diferiram entre si $(\mathrm{P}>0,05)$. Em relação ao tempo despendido, verificou-se que o processo amostral alterou $(\mathrm{P}<0,05)$ a eficiência do processo de filetagem, ou seja, a intervenção do pesquisador, para que fossem feitas as pesagens, ampliou o tempo gasto. Não houve variação $(\mathrm{P}>0,05)$ no rendimento de filetagem entre as categorias de peso, 1 (300-600g), 2 (601-800g) e 3 (801$1000 \mathrm{~g})$. Souza et al. (1997a,b) e Souza (2003) relataram diferenças no rendimento de filetagem de acordo com as categorias de peso. Nesses estudos, foram utilizados peixes pequenos e em pequena escala, o que não ocorreu no presente trabalho. Os percentuais de filés para os peixes classificados e para os não classificados foram de $30,7 \%$ e de $28,6 \%$, respectivamente. Observa-se tendência de rendimento de filetagem maior nos peixes classificados.

As variações em rendimentos de filetagem, ao longo de todo o período do experimento $(28,9 \%$ a $33,6 \%$ ), podem ter ocorrido em conseqüência da falta de padronização dos pesos das tilápias, pois o agrupamento experimental ocorreu apenas em algumas oportunidades. $\mathrm{O}$ tamanho das tilápias, aliado ao fator humano, possivelmente, são os principais condicionantes do rendimento industrial final.

Torna-se, portanto, essencial considerar a importância do fator humano como condicionante do rendimento da filetagem. Desde a montagem do experimento, já havia a premissa de que este fato seria fundamental no processo. No dia 29/04/2004, verificou-se o rendimento de $28,9 \%$, o menor durante todo o estudo. Ao levantar as causas dessa ocorrência, notou-se que os funcionários estavam desanimados e sem motivação para trabalhar, devido a problemas internos da empresa. Um outro fator, que possivelmente influenciou no rendimento dos funcionários, foi a permissão dada aos mesmos de levarem o produto resultante de toilet para casa; nessas ocasiões, houve queda de rendimento.

Ainda com respeito ao desempenho dos funcionários, percebeu-se que a presença de pessoas estranhas, ou qualquer outra modificação na rotina, alterava o tempo de processamento. Isso foi demonstrado quando da realização das três medições integrais. Esperava-se que aqueles que cumpriam o turno de trabalho tivessem $o$ desempenho usual $(2,073 \mathrm{~kg} / \mathrm{min}$ de peixe processado) e não o verificado $(0,854 \mathrm{~kg} / \mathrm{min})$. Esse procedimento pode ser explicado pelo fato de os funcionários considerarem que a coleta de dados poderia ter ligações com a verificação do seu desempenho, o que os fizeram gastar mais tempo, para realizar o mesmo serviço.

Não houve diferença no rendimento de filetagem, em relação ao peso final do respectivo filé, $31,2 \%$, na presença da equipe extra (rendimento amostral) e 30,4\%, sem equipe extra (rendimento industrial). Isso pode significar que os processadores gastavam mais tempo, na tentativa de obter melhor rendimento, quando em presença do pesquisador. Essas diferenças podem ser bastante significativas sob o ponto de vista econômico, de acordo com o volume final produzido no prazo de um ano.

Quanto ao valor econômico derivado do rendimento da filetagem, supondo-se que os resultados (Tab. 1) reflitam a realidade industrial, multiplicou-se o peso total de filés (fresco e congelado) produzido no ano de $2003(36.400 \mathrm{~kg}$, equivalente a $31 \%$ de rendimento de filetagem médio anual) pelo seu valor médio em reais, para o mercado interno $(13,00 \mathrm{R} \$ / \mathrm{kg})$, o que resultou em R\$ 473.200,00. A partir daí, estimou-se o valor da produção total de filé, considerando os dois extremos de rendimento de filetagem $28,9 \%$ $(33.934 \mathrm{~kg})$ e $33,6 \%(39.453 \mathrm{~kg})$. A diferença entre eles $(5.519 \mathrm{~kg})$, corresponderia a $\mathrm{R} \$$ $71.747,00$, o que é expressivo economicamente.

Ainda neste contexto, fazendo-se simulações semelhantes, tem-se que a diferença de $0,8 \%$ 
entre o rendimento de filetagem amostral $(31,2 \%)$ e o rendimento de filetagem industrial $(30,4 \%)$ representaria um valor da ordem de $\mathrm{R} \$$ $12.212,00$ ao ano $(939,4 \mathrm{~kg} / \mathrm{ano})$. Esse valor, para uma empresa do porte dessa examinada, significa um percentual apreciável na sua redução de custos.

\section{REFERÊNCIAS BIBLIOGRÁFICAS}

BRASIL. Ministério da Agricultura, Pecuária e Abastecimento. Institui o Sistema de Análise de Perigos e Pontos Críticos de Controle. Portaria n. 46, de 10 de fev.1998. Brasília: Ministério da Agricultura, Pecuária e Abastecimento. 1998.

BRASIL. Ministério da Saúde. Portaria n. 326 de 30 de jul.1997. Diário Oficial da União, 01 ago. 1997. Seção 1.

CLEMENT, S. Comparison of processing yield and nutrient composition of cultured tilapia and channel catfish. 1992. 20f. Thesis (Master of Science) - Auburn University, Auburn.

CLEMENT, S.; LOVELL, R.T. Comparison of processing yield and nutrient composition of culture Nile tilapia (Oreochromis niloticus) and channel catfish (Ictalurus punctatus). Aquaculture. v.119, p.299-310, 1994.

MACEDO-VIEGAS, E.M.; SOUZA, M.L.R.; KRONKA, S.N. Estudo da carcaça de tilápia do Nilo (Oreochromis niloticus), em quatro categorias de peso. Rev. Unimar, v.19, p.863$870,1997$.

PÁDUA, D.M.C.; SILVA, P.C.; FRANÇA, A.F.S. et al. Produção e rendimento de carcaça da Tilápia Nilótica, Oreochromis niloticus, alimentada com dietas contendo farelo de milheto. 4 p. 1998. Disponível em: $<$ http//:www.sbz.org.Br/eventos/PortoAlegre/ho mepagesbz/Peq/ PEQ002.htm>. Acessado em 28 de agosto de 2003.

RIBEIRO, L.P.; MIRANDA, M.O.T. Rendimentos do processamento do surubim Pseudoplatystoma coruscans. In: MIRANDA, M.O.T. (Org.). Surubim. Brasília: IBAMA, 1997. p.101-111 (Coleção Meio Ambiente, Série Estudos Pesca, ...).
SAMPAIO, I.B.M. Estatística aplicada à experimentação animal. 2.ed. Belo Horizonte: Fundação de Estudo e Pesquisa em Medicina Veterinária e Zootecnia, 2002. 265p.

SOUZA, M.L.R. Industrialização, comercialização e perspectivas: fundamentos da moderna aqüicultura. Canoas: Ed. ULBRA, 2001. p.149189.

SOUZA, M.L.R. Processamento do filé e da pele da Tilápia do Nilo (Oreochromis niloticus): Aspectos tecnológicos, composição centesimal, rendimento, vida útil do filé defumado e testes de resistência da pele curtida. 2003. 166f. Tese (Doutorado) - Centro de Aqüicultura, UNESP, Jaboticabal.

SOUZA, M.L.R., MACEDO-VIEGAS, E.M.; KRONKA, S.N. Efeito do método de filetagem e categorias de peso sobre o rendimento de carcaça, filé e pele da tilápia do Nilo (Oreochromis niloticus). In: REUNIÃO ANUAL DA SOCIEDADE BRASILEIRA DE ZOOTECNIA, 34., 1997, Juiz de Fora. Anais... Juiz de Fora: SBZ, 1997a.

SOUZA, M.L.R.; MACEDO-VIEGAS, E.M. Comparação de quatro métodos de filetagem utilizado para a tilápia do Nilo (Oreochromis niloticus) sobre o rendimento do processamento. Infopesca Internacional, Uruguay, 2001. p.26-31.

SOUZA，M.L.R.; MACEDO-VIEGAS， E.M.; FARIA, R.H.S. et al. Análise quantitativa do processo de defumação e avaliação sensorial de filés de tilápia do Nilo (Oreochromis niloticus) e pacu (Piaractus mesotamicus). In: AQÜICULTURA BRASIL, 2002, Goiânia. Anais... Goiânia: Abraq. 2002. p.228.

SOUZA, M.L.R.; MACEDO-VIEGAS, E.M.; KRONKA, S.N. Estudo da carcaça da tilápia do Nilo (Oreochromis niloticus) em diferentes categorias de peso. In: REUNIÃO ANUAL DA SOCIEDADE BRASILEIRA DE ZOOTECNIA, 34., 1997, Juiz de Fora. Anais... Juiz de Fora: SBZ, $1997 b$.

SOUZA, M.L.R.; MACEDO-VIEGAS, E.M.; KRONKA, S.N. Influência do método de filetagem e categorias de peso sobre rendimento de carcaça, filé e pele da tilápia do Nilo (Oreochromis niloticus). Rev. Bras. Zootec., v.28, p.1-6, 1999. 